\title{
The Evolving Use of New Media with Young Children in Libraries
}

\author{
KATHLEEN CAMPANA, J. ELIZABETH MILLS, MARIANME MARTENS, AND CLAUDIA HAINES
}

$\mathrm{T}$ he topic of using new media with young children (zero to five years old) in the library has been a focus of conversations in the field for several years. ${ }^{1}$ An Association for Library Service to Children (ALSC) survey, administered to children's library staff from across the United States in 2014, provided a foundation for these conversations by revealing how library staff were using new media with young children and their families. The results of the survey, which revealed widespread inclusion of new media in library spaces, along with the innovative work of library staff and community needs, spurred profession-wide initiatives to apply research-based practices to how libraries support the literacy and media needs of families.

Building on this survey, in 2015 the ALSC Board of Directors responded to the growing use of new media with young children, and the expanding role library staff can play in the lives of families, by adopting the white paper Media Mentorship in Libraries Serving Youth. The white paper provided a definition of media mentorship and articulated why this work is an important aspect of library service to children. To further guide library staff who work with children and families, ALSC, Cen Campbell, and Claudia Haines published the book Becoming a Media Mentor: A Guide for Working with Families (ALA Editions, 2016).

During the same period, staff trainings on the use of new media in the library with young children increased nationwide. Several states and library systems have since created local and regional programs to provide ongoing professional development, grants for new technology, and family support campaigns. These include libraries in Arizona, Massachusetts, Maryland, Washington, Alaska, California, New York, and Ohio, among others. ALSC and many library systems now incorporate media mentorship and new media into their youth services professional competencies to reflect the needs of libraries. Furthermore, master of library and information science (MLIS) programs at Kent State, San José State, the University of Washington, and others have integrated new media into core courses, recognizing the evolving role of future children's librarians.

In 2015, then ALSC President Ellen Riordan compiled a task force to examine how ALSC could recognize new media. Based on their recommendations, ALSC established the Excellence in Early Learning Digital Media Award, first awarded in 2019, recognizing producers of excellent digital media for kids ages two to eight years, and the Notable Children's Digital Media list, first released in 2018, selects exemplary, interactive media that provides accurate content, entertains, and supports active learning and joint media engagement for children fourteen years of age and younger. Both the award and the notable list provide children's library staff and families with recommendations for high-quality media designed for young children.

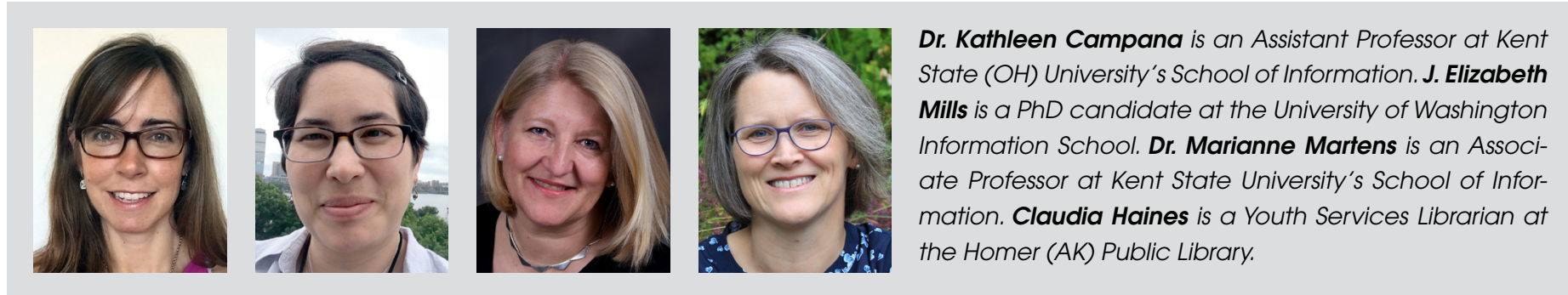


Apps and other new media, like the programmable Code-aPillar or Cubetto that allow young children to learn about coding and computational thinking, are finding their way into public library family programming. These new tools are incorporated into library initiatives that support STEM (Science, Technology, Engineering, and Math) and STEAM (STEM + Art). This follows an increased focus nationwide on supporting literacy and learning across academic fields in informal learning centers like libraries.

Given these changes, ALSC commissioned an additional survey in 2018 to find out what has changed with new media use in the library with young children. In light of these library initiatives, growth in the quantity and kinds of new media available for young children and widely available media mentorship training, the goal of the survey was to understand how, if at all, the use of new media in libraries with young children and their caregivers has changed since 2014.

\section{Literature Review}

When research began on using new media in the library with young children in 2014, there were already conflicting views among parents, caregivers, teachers, and librarians about the use of technology (at the time, mostly tablets) with young children. While many saw benefits in multimodal learning tools, others felt that new media was a distraction that interfered with young children's early literacy skills. Since then, while conflicting views remain, more has been uncovered. Parents and caregivers use technology with young children for a variety of reasons, such as they are avid users themselves and share it with their children; they feel it is an important part of school readiness; or they have found benefits with new media as assistive devices for children with a disability.

As of 2019, whether those who interact with young children are pro- or anti-tech, new media is here to stay. Screens are pervasive in everyday life in the United States. In fact, according to the Pew Research Center's 2018 Mobile Fact Sheet, in 2018, 95 percent of adult Americans owned some type of smartphone, 73 percent owned a desktop or laptop computer, and 53 percent owned a tablet. ${ }^{2}$

In addition, the 2017 Common Sense Media Census found that 95 percent of zero to eight-year-olds have a smartphone in the home, 78 percent have a tablet in the home, and 42 percent have their own tablet. ${ }^{3}$ Furthermore, a 2016 study by the Erikson Institute found that 85 percent of parents surveyed allowed their children under the age of six to use new media. ${ }^{4}$ Schools are increasingly using new media for testing-as early as kindergarten-and many parents feel that using new media at home is an important part of school readiness. ${ }^{5}$
In addition to playing a role with school readiness, new media devices are frequently being used to support the needs of children with a disability. In several studies, tablets, such as iPads, were found to have benefits when it comes to serving the literacy needs of children with a disability. ${ }^{6}$ In addition, certain iPad apps have been found to be helpful literacy tools for students struggling to learn to read. ${ }^{7}$ Finally, Paciga and Donohue found that technology and interactive media could support whole child development. ${ }^{8}$

When the first survey was conducted in 2014, merely four years after the launch of the first iPad, new media in libraries usually referred to tablets or to AWE Learning stations. ${ }^{9}$ However, by 2018, other new media tools also encompassed tangible and programmable tech, such as Code-A-Pillars and Snap Circuits, in addition to tablets. A move toward including computational thinking in early literacy programming makes these tools perfect for challenging library staff to explore the relationship between early literacy and computational thinking skills when working with young children and their caregivers. $^{10}$

\section{Background}

The original Young Children, New Media, and Libraries survey was conducted because a team of researchers determined that an initial snapshot of the landscape of new media use around the country, in library programs and services for young children, could provide powerful material for advocacy and development. This led to the launch of the first nationwide survey of public libraries to investigate emergent technology use in programs and services for children aged zero to five and their families. The survey was conducted in collaboration with ALSC, LittleeLit.com (once a blog, now a web-based think tank), and the iSchool at the University of Washington.

The overarching research question guiding the 2014 study was, What is the landscape in public libraries around the country with respect to new media use with young children and their caregivers? The goals of the study were to understand to what extent new media was being used in libraries and what types were being used, if it was being used in programming for young children, what kind of funding and selection strategies librarians were using in procuring new media, and plans for the future with regards to new media use.

To achieve these goals the survey included questions on topics related to new media use with young children in the library. The survey was administered in August of 2014, was available for participation for eighteen days, and drew responses from more than four hundred library staff from around the country. ${ }^{11}$ 


\section{The 2018 Survev}

In late 2017, due to recent changes in research-based new media practices and guidelines from the field of education, the American Academy of Pediatrics (AAP), and persistent debates among librarians about using new media with young children in the library, we were asked by ALSC to readminister the 2014 Young Children, New Media, and Libraries survey. The overarching research question guiding the study remained the same as it was in 2014: What is the landscape in public libraries around the country with respect to new media use with young children and their caregivers? We also added a second research question: What changes are present in the data from 2018 when compared to the data from 2014 in terms of new media use with young children?

As one of the goals for the 2018 survey was to determine if there had been any changes in the landscape from 2014 to 2018, we repeated the original 2014 survey questions. In addition, we decided to add some supplemental questions to gain insight into other aspects of new media use with young children and their caregivers in the library. The final survey design included twenty-nine questions, consisting of both the original questions from the 2014 survey, as well as additional questions on topics such as librarians' attitudes toward providing access to new media for young children and their caregivers, the challenges librarians face in using new media, and more.

However, this article will focus on the findings that emerged from the original questions in the 2018 survey and the comparison of the findings from the 2014 to 2018 surveys..$^{12}$ Most of the original questions were multiple choice with some short answer boxes where participants could add additional detail.

The second survey was administered in August of 2018. Prior to opening the survey to the public, it was pilot-tested with a variety of children's library staff across the country. Following the pilot-testing phase, we opened the survey to all library staff at the beginning of August and left it open for the entire month. The survey was initially distributed through various public library listservs and groups with regular reminders to complete the survey being sent out through the same channels.

When the survey closed, we had 262 responses. ${ }^{13}$ The respondents represented libraries of all sizes. However, the highest number of respondents represented libraries serving 10,000 to 24,999 individuals. The second highest response rate came from libraries serving 25,000 to 49,999 , followed by libraries serving fewer than 5,000. We also saw a bimodal distribution, with an initial peak among respondents serving fewer than 5,000-curiously the same distribution we saw in 2014 (see figure 1).

One factor we learned about in 2014 that may be influencing this distribution is that many libraries in the under-5,000 category were often able to get grants, because of their size, to obtain the funds to purchase new media devices for their libraries.

\section{Results}

The data from the 2018 survey provides insight into the landscape of public libraries' new media use with young children. Overall, the respondents were using several different types of new media with their patrons through a variety of methods. In the sections that follow, we first present the 2018 findings from each question more in-depth, according to each library's reported size. To more clearly present this data from across the different sizes of libraries, we collapsed the libraries into three broader size categories based on legal population: small ( 0 to 24,999$)$, medium $(25,000$ to 249,999$)$, and large $(250,000$ to $1,000,000)$. We presented the data in this way because different-size libraries have access to varying amounts of resources, have fluctuating constraints, and serve communities with different characteristics.

We then explored how the data from the 2018 survey compared to the results from the 2014 survey, looking at overall response frequency for this comparison. For this data, we wanted to examine the differences and similarities in terms of use and access across all our respondents, regardless of library size, in order to emphasize the specific findings under each question. This broad look enabled us to understand how the field as a whole has changed since the 2014 survey in terms of the use of new media with young children and their caregivers.

\section{Figure 1. Participating libraries by legal service population}

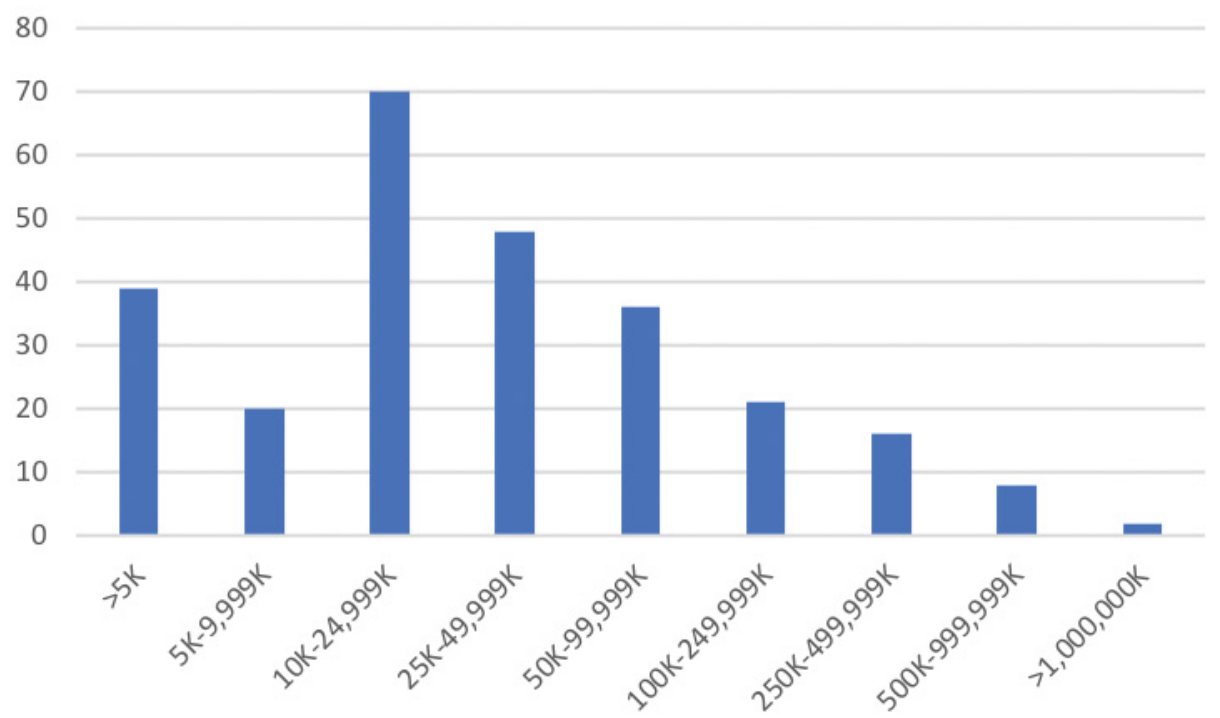




\begin{tabular}{lccc}
\hline Device Type & $\begin{array}{c}\text { Percentage of Small } \\
\text { Libraries Using the } \\
\text { Device in 2018 }\end{array}$ & $\begin{array}{c}\text { Percentage of Medium } \\
\text { Libraries Using the } \\
\text { Device in 2018 }\end{array}$ & $\begin{array}{c}\text { Percentage of Large } \\
\text { Libraries Using the } \\
\text { Device in 2018 }\end{array}$ \\
\hline Children's tablet (e.g., Nabi, LeapPad) & 25.58 & 30.47 & 9.52 \\
\hline Combination e-reader/tablet (e.g., Kindle Fire or Nook Tablet) & 10.07 & 0.00 \\
\hline Digital recording device (e.g., digital camera, Flip Video, GoPro) & 3.87 & 6.66 \\
\hline MP3 players (e.g., iPod or other music player) & 14.72 & 16.19 & 3.84 \\
\hline Devices that are multilingual for non-native English speakers & 12.40 & 14.28 \\
\hline Programmable tech (e.g., Beebots, Code-a-Pillar, Cubetto) & 30.23 & 39.04 \\
\hline Projection device (e.g., device to display song lyrics) & 18.60 & 28.57 \\
\hline Proprietary institutional devices (e.g., AWE or Hatch stations) & 55.03 & 53.33 \\
\hline Tablet (e.g., iPad, iPad Mini, Galaxy Tab, Nexus 7, etc.) & 42.63 & 53.33 \\
\hline Tangible tech (e.g., Makey Makeys, Osmo, Squishy Circuits) & 33.33 & 40.00 \\
\hline
\end{tabular}

\section{Table 2. Comparison of Responses from 2014 to 2018, Ranked in Decreasing Order by 2018 Percentages}

\begin{tabular}{lcc}
\hline Device Type & $\begin{array}{c}\text { Percentage of Libraries } \\
\text { Using the Device in 2014 }\end{array}$ & $\begin{array}{c}\text { Percentage of Libraries } \\
\text { Using the Device in 2018 }\end{array}$ \\
\hline Proprietary institutional devices & 43.77 & 43.82 \\
\hline Tablet & 47.68 & $\mathrm{n} / \mathrm{a}$ \\
\hline Tangible tech & $\mathrm{n} / \mathrm{a}$ & 37.02 \\
\hline Programmable tech & 10.76 & 35.88 \\
\hline Children's tablet & $\mathrm{n} / \mathrm{a}$ & 26.72 \\
\hline Projection device & 10.76 & 22.90 \\
\hline MP3 players & 10.76 \\
\hline Devices that are multilingual for non-native English speakers & 22.49 \\
\hline Combination e-reader/tablet & 14.89 \\
\hline Digital recording device & 10.27 \\
\hline
\end{tabular}

\section{Types of Devices}

To understand the types of devices that libraries are using with young children and their caregivers, one of the questions asked the participants to select all of the different types of devices they use with this population. Several different types of devices were provided as multiple-choice options, as well as the option for "none" or "other." Many libraries indicated that they were using more than one type of device with young children and their caregivers. Across all respondents, the average number of different types of devices used with young children and their caregivers was three.

When looking at devices used across the different sizes of libraries, there are some clear trends that emerge (see table 1). Across all three groups, proprietary devices (i.e., AWE stations and others) were the most popular type of device. However, for the libraries in the medium size group, tablets were equal to the proprietary devices in terms of use. For small libraries, tablets were the second most popular device type. For the larger libraries, tangible and programmable overtook tablets in popularity. This could indicate that for larger libraries, with larger budgets, tangible and programmable tech devices are becoming more prevalent in programming and are more well-known to the patrons, who then want to see them and use them in the library. Children's tablets, projection devices, MP3 players, and multilingual devices were also moderately popular across all three size categories. In addition, 18 percent of respondents selected the "other" option to indicate they used devices not covered by these categories, such as laptops and desktops, gaming systems, iPhones with virtual reality available, and multilingual CDs which were mostly used for language learning. Finally, 11 percent of the respondents indicated that they did not have any new media available to young children and their caregivers.

There are several points of comparison between the 2018 and 2014 findings (see table 2). In 2018 and 2014, proprietary institutional devices and tablets were the two most popular devices. In 2018, tangible new media and programmable new media were a close second, but they were not included in the 2014 survey because they were not yet prevalent in library 


\begin{tabular}{lccc}
\hline Method of Device Access & $\begin{array}{c}\text { Percentage of Small } \\
\text { Libraries Offering Each } \\
\text { Method of Access }\end{array}$ & $\begin{array}{c}\text { Percentage of Medium } \\
\text { Libraries Offering Each } \\
\text { Method of Access }\end{array}$ & $\begin{array}{c}\text { Percentage of Large } \\
\text { Libraries Offering Each } \\
\text { Method of Access }\end{array}$ \\
\hline Checkout for use outside of the library & 28.68 & 37.14 & 19.23 \\
\hline Checkout for use within the library & 27.13 & 39.05 & 19.23 \\
\hline Device used in library program (other than storytime) & 51.16 & 65.71 & 54.29 \\
\hline Device used in storytime & 45.74 & 21.90 & 61.54 \\
Mentoring families & 17.83 & 1.90 & 11.54 \\
Mentoring families with bilingual content & 1.55 & 59.05 & 7.69 \\
\hline Tethered or mounted devices & 58.91 & 57.69 &
\end{tabular}

\section{Table 4. Comparison of Methods of Device Access from 2014 to 2018 , Ranked by 2018 Percentages}

\begin{tabular}{|c|c|c|}
\hline Method of Device Access & $\begin{array}{l}\text { Percentage of Libraries } \\
\text { Using Each Method of } \\
\text { Device Access in } 2014\end{array}$ & $\begin{array}{l}\text { Percentage of Libraries } \\
\text { Using Each Method of } \\
\text { Device Access in } 2018\end{array}$ \\
\hline Tethered or mounted devices & 40.7 & 58.5 \\
\hline Device used in library program (other than storytime) & 30.6 & 57 \\
\hline Device used in storytime & 40.2 & 51.7 \\
\hline Checkout for use outside of the library & 19.5 & 31.9 \\
\hline Checkout for use within the library & 25.7 & 28.8 \\
\hline Mentoring families & 21.6 & 18.6 \\
\hline Mentoring families with bilingual content & 2.1 & 2 \\
\hline
\end{tabular}

settings. Looking across 2014 and 2018, there were increases in several types of new media, including proprietary devices and children's tablets, multilingual devices, and MP3 players. Finally, use of e-readers and digital recording devices dropped off significantly from 2014 to 2018.

\section{Device Access}

To provide insight into how libraries are using new media with young children and their caregivers, the participants were asked to indicate all of the different ways they provide young children and their caregivers with opportunities to access these types of new media. Various common methods were provided as multiple-choice options, as well as the option for "none" or "other." Many libraries indicated that they were using new media in multiple ways with young children and their caregivers, and some common themes emerged in the data (see table 3).

Tethered or mounted devices were the most popular way to use new media with young children for small libraries, followed closely by using new media in storytimes and other programs. Alternatively, using new media in programs, both storytimes and other programs, was more popular in medium and large libraries, though having tethered or mounted devices was almost as common. Across all three size groups, device mentoring and offering devices for checkout to use outside of and inside the library were the next most frequent responses. The remaining options-other, none, and mentorship for multilingual devices-were selected at very low rates.

In 2018, libraries most commonly provided access to new media devices through tethering in libraries, use in storytimes, and use in other programs besides storytimes. This mirrors the findings from 2014 (see table 4). Looking across the 2014 and 2018 responses there were increases across all of the methods except for device mentoring, which decreased from 2014 to 2018. There were also significant increases in the responses of offering tethered devices and devices in programs other than storytimes. We saw smaller increases in devices being used in storytimes and devices available for checkout outside of the library. Providing devices for checkout outside of the library can be crucial for young children and families who might otherwise not have access, so this increase is a step in the right direction of providing access to new media for all families.

\section{Funding Sources for Devices}

The survey included a question on how libraries are funding the devices they use with young children and their caregivers. A list of common funding sources was provided, and 
participants were able to select all of the various sources they had used to acquire the devices they were using with young children. Overall, many libraries were using multiple funding sources to fund the devices they were using with young children and their caregivers (see figure 2). Across all of the size categories, the most common funding source was the libraries' operating budgets, followed by grants and monetary donations from groups such as the Friends of the Library. Staff-owned devices and in-kind donations were not as common, having been indicated in only a small percentage of responses. Finally, only 7 percent of respondents across all library size categories selected "other," sharing that they acquired their devices through promotion, through checkout from the state library or district office, or that they weren't sure since the devices predated them at the library.

The comparison between the 2014 and 2018 data once again yielded similar results (see figure 3). The 2018 and the 2014 data both revealed that a library's operational budget, grant funds, and other monetary donations were the three most common sources of funding for new media devices. Looking across the 2014 and 2018 results there were increases in all of the funding source categories but one. The largest increase was in funding through the library's operational budget, which jumped from 56 percent to 76 percent. At the same time, staff use of their own personal devices in programming decreased from 2014 to 2018. When combined with the increases in the operational budget and grant funding, this decrease suggests that libraries may view these devices as an important part of their services and are working to fund them through their own budget and other funding streams so that staff do not need to use their own devices.

\section{Resources for Selecting and Using Devices}

A question was included in the survey to understand what resources library staff are using to inform their selection and use of new media with young children. A multiple-choice list was provided of the types of resources, including options for "other" or "none," and respondents were allowed to select all that apply. The data from the question revealed that library staff are using a variety of resources to understand what devices to use and how to use new media effectively with families of young children (see table 5). For medium and large

\section{Figure 2.2018 Percentages of Library Funding Sources for Purchasing New Media, by Library Size}

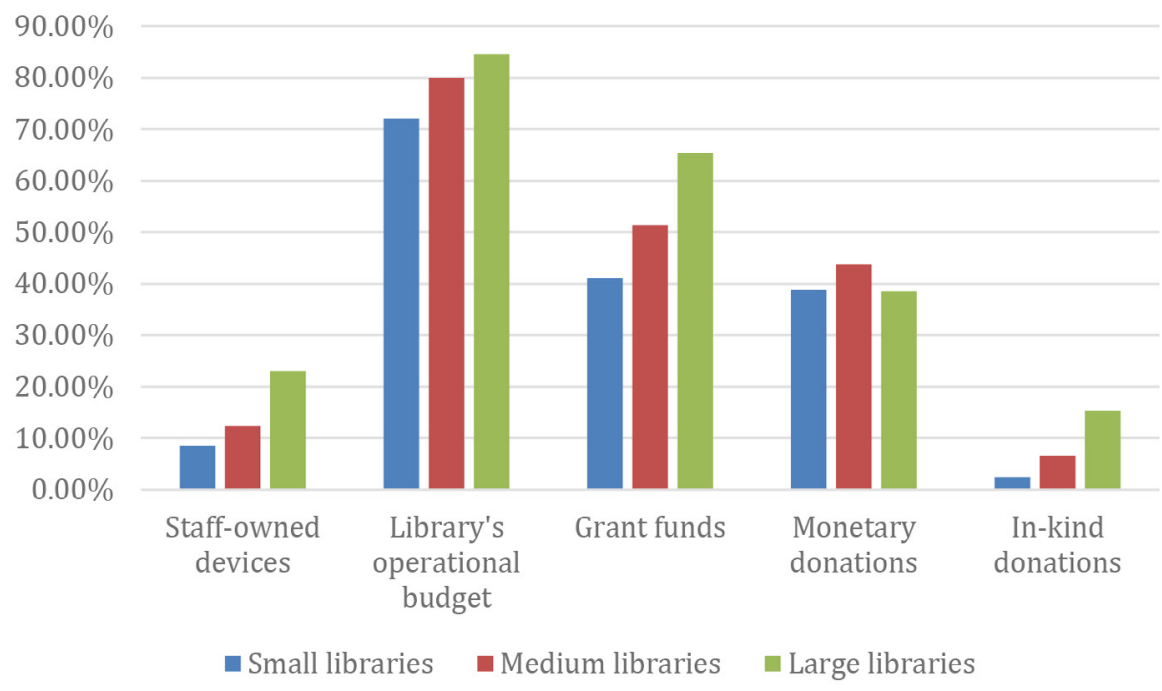

Figure 3. Comparison of 2014 and 2018 Funding Sources

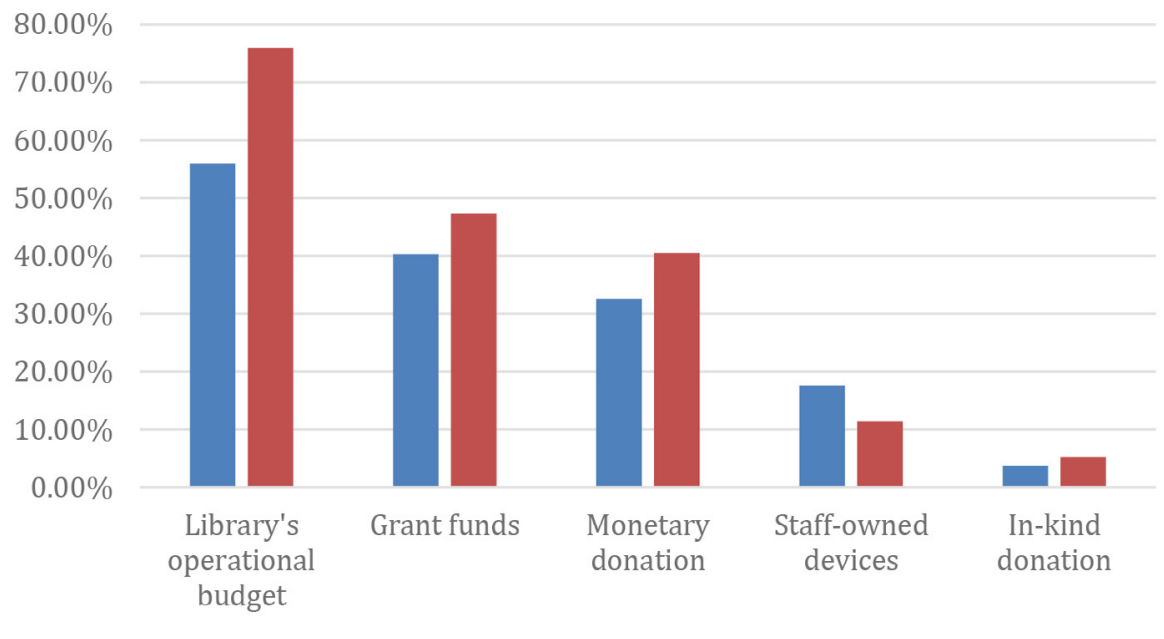

— $2014 \square 2018$ libraries, professional journal articles and professional organizations received the highest number of responses, but for small libraries, recommendations from colleagues received the most responses, followed by in-person training and websites. These findings suggest the power of peer networks in this kind of decision-making process as well as the need for a continued role for ALSC and its committees to develop and offer trainings related to children, technology, and media mentorship to guide the field. Finally, 25 percent of participants selected "none," which could suggest that these library staff don't feel the need for resources to guide their new media practices or are unaware of the existence of such resources.

When comparing the 2018 data to the 2014 data, the findings were fairly similar (see table 6 ). The largest increase occurred in recommendations from colleagues, which jumped from 26 to 37 percent. This may be due to more library staff gaining 


\begin{tabular}{lccc}
\hline Types of Resources & $\begin{array}{c}\text { Percentage of Small } \\
\text { Libraries Using Each } \\
\text { Type of Resource }\end{array}$ & $\begin{array}{c}\text { Percentage of Medium } \\
\text { Libraries Using Each } \\
\text { Type of Resource }\end{array}$ & $\begin{array}{c}\text { Percentage of Large } \\
\text { Libraries Using Each } \\
\text { Type of Resource }\end{array}$ \\
\hline In-person event and/or training & 26.36 & 33.33 \\
\hline Online event and/or training & 10.85 & 13.33 & 34.62 \\
\hline Professional journal articles or books & 21.71 & 47.62 & 37.14 \\
\hline Professional organizations & 16.28 & 23.08 \\
\hline Recommendation from colleagues & 33.33 & 50.00 \\
\hline Social media (e.g., blog, Facebook, Twitter) & 10.85 & 18.10 & 50.00 \\
\hline Websites & 26.36 & 25.71 & 26.92 \\
\hline
\end{tabular}

\section{Table 6. Comparison of 2014 and 2018 Resources Consulted, Ranked by 2018 Percentages}

Types of Resources

\begin{tabular}{llc}
\hline Recommendation from colleagues & 26.8 & 37.9 \\
\hline Professional journal articles or books & 30.6 & 35.1 \\
\hline In-person event and/or training & 28.1 & 30.3 \\
\hline Professional organizations & $\mathrm{n} / \mathrm{a}$ & 27.8 \\
\hline Websites & 23.0 & 24.3 \\
\hline Social media (e.g., blog, Facebook, Twitter) & 15.8 & $\mathrm{n} / \mathrm{a}$ \\
\hline Online event and/or training & 13.9 \\
\hline
\end{tabular}

experience and familiarity with using new media with young children, to the point where they are comfortable providing guidance to their peers. The relatively even distribution of the responses in both 2014 and 2018 suggests that staff are still using a wide variety of resources to decide what to purchase for their library.

\section{Future Plans for New Media Use with Young Children and Their Caregivers}

The survey also included a question to understand libraries' future plans for the availability and use of new devices with young children and their caregivers. A multiple-choice list, including options for "other" and “don't know," was provided; respondents could select only one answer. Regarding future plans for new media use with young children, libraries seem eager to continue using new media devices with young children and their caregivers, with a majority of small, medium, and large libraries indicating that they plan to increase the availability of these devices in their community (see figure 4). Some libraries in these categories indicated plans to stay at the same level of device availability and usage. This may be because they have only recently introduced devices in their library and want to see the impact. None of the libraries across all three size categories indicated plans to eliminate usage, and only one library across all three size categories indicated a decrease in availability.
Across both the 2014 and 2018 surveys, the findings regarding future plans for new media remain almost the same (see figure 5). There was a small decrease from 2014 to 2018 in the amount of responses indicating plans to increase the availability of new media devices, while there was an increase from 2014 to 2018 in responses planning to keep the availability of devices roughly the same. These findings together suggest that, because new media is no longer as novel as it was in 2014, some libraries may have reached a saturation point in the amount of new media that they want to make available, and as a result they plan to keep their availability at the same level.

\section{Discussion}

These findings provide insight into the two research questions guiding the study:

- What is the landscape in public libraries around the country with respect to new media use with young children and their caregivers?

- What changes are present in the data from 2018 when compared to the data from 2014 in terms of new media use with young children?

The findings from the 2018 survey demonstrate that the landscape of public library new media use with young children and 
their caregivers is abundant. Libraries continue to use a variety of different devices with young children and their families in many different ways. This is important because we know that caregivers are using technology with young children and that their usage has increased since $2014 .{ }^{14}$ Given that caregivers often feel uncertain about how to use new media with young children effectively and what to use, libraries are well-positioned to support families with young children in their community by helping them understand how to use new media with their young children in an effective manner. ${ }^{15}$

The results from the survey questions on funding sources, resources consulted, and future plans for new media all provide further insight into public library new media use with young children and their caregivers. The fact that libraries are predominantly funding new media devices through their operational budgets speaks to the emphasis they are placing on these devices as an important part of their collection and services. These findings also demonstrate that library staff are using a variety of resources in making their device and usage decisions. This suggests that library staff want to be better equipped to select and use new media with young children. However, the fact that library staff are having to turn to a variety of sources for guidance also seems to indicate a need for additional, more comprehensive professional development that helps children's staff understand how to select and use new media with young children and their families. Additionally, as a majority of respondents indicated that their use and offerings of technology in youth services will increase in the future, it is reasonable to conclude that this topic-new media in library services for young children-will continue to be an important one for the profession.

Looking at the 2018 data alongside the 2014 data provides insight into any changes that occurred in between the two surveys. Given the similarities between the results of the two surveys, it appears that libraries have continued to move forward with the new media efforts that were first uncovered with the 2014 survey. Furthermore, some of the increases in the 2018 survey suggest that libraries have worked to grow and expand their new media use with young children and their caregivers. In particular, there were large increases in the percentage of libraries who had devices tethered in their spaces for families to use, were using new media in their storytimes and other programs for young children, and were checking out new media for use outside of the library. This suggests that libraries are recognizing the importance of providing access and exposure to these new media devices for families in their communities.

The fact that libraries are providing access to new media devices for young children and their families is important because many children and their families cannot afford to have these devices at home. The 2018 findings suggest that libraries appear to have recognized their role in meeting the needs of these families by increasing the tethered devices they have in their spaces and the devices that they have available for checkout outside of the library. In examining media use by children ages zero to eight for Common Sense Media, Rideout found that while "the digital divide has narrowed, [it] still remains an issue." ${ }^{\prime 6}$ By providing access to these devices, libraries are helping to narrow this divide and give children exposure to these devices and the content supplied by them 
so that the children have similar opportunities to their peers to learn from and build proficiency with new media devices.

While the libraries who participated in the survey have been successful with providing access to devices for young children and their families, mentorship remains an area of growth for libraries in new media use with young children, with the 2018 survey supporting one of the main findings from the 2014 survey:

\footnotetext{
Libraries are in a position to be digital hubs, apparent in [the] data by the quantity and scope of new media device use and availability. However, there is less evidence of mentorship being provided currently by library staff within these emerging hubs, despite data that show widespread use of tablets and media players in storytimes with young children, as well as other device use outside of library storytimes. ${ }^{17}$
}

The number of participants who indicated they were providing mentorship decreased from 21.6 percent in 2014 to 18.6 percent in 2018. Furthermore, in the 2018 survey, mentorship ranked last in terms of frequency of responses for how libraries were using new media with their families. These results may be due to a variety of reasons, but given that Livingstone, Blum-Ross, and Pavlick found that "Parents have few resources to turn to either when they or their children run into problems or when they want positive recommendations," we know that there is a need for families to have a place to turn when they need guidance on using new media with their young children..$^{18}$ Libraries are well-situated to play this role, so the question then arises-how can libraries effectively position themselves to take on this role in terms of staff preparation and in the eyes of the families in their communities?

\section{References and Notes}

1. A variety of terms can and have been used to refer to the various digital devices and content that have become prevalent in our society. For the purposes of this study we chose to use the term "new media" to refer to these devices, as that is the terminology that was used in the 2014 survey.

2. Pew Research Center, "Demographics of Mobile Device Ownership and Adoption in the United States," Pew Research Center: Internet \& Technology, February 5, 2018, www.pewinternet.org/fact-sheet/mobile.

3. Victoria Rideout, The Common Sense Census: Media Use by Kids Age Zero to Eight (San Francisco: Common Sense Media, 2017): 263-83.

4. "Erikson Institute Report on Technology and Young Children," November 2, 2016, http://sites.gsu.edu/best practices/2016/11/02/erikson-institute-report-on -technology-and-young-children.

5. Brigitte Vittrup et al., "Parental Perceptions of the Role of Media and Technology in Their Young Children's Lives," Journal of Early Childhood Research 14, no. 1 (March 2016): 43-54, https://doi.org/10.1177/1476718X14523749.

\section{Conclusion}

This article provides insight into the landscape of new media use by libraries with young children and their caregivers. The findings demonstrate that the landscape is rich with a variety of new media use and has grown somewhat since 2014 . In addition to offering insight into the new media landscape with libraries and young children, the survey findings also point to important areas for further research. While libraries are using new media with young children and their families, research is needed that explores the impact of digital tools on young children's early literacy and learning development so that libraries and families can be more effective with their new media use. Research is also needed to provide depth to, and an expansion of, the findings discussed here. Given that the survey revealed an increased usage of new media in programs for young children, it would be useful to understand more about how libraries are using new media in programs. It is also important to understand what families want from the library with regard to new media use and how libraries can best support families with their new media needs.

This survey, along with the one done in 2014, offers important evidence of how libraries are using new media with young children. Having this baseline understanding is crucial for the field to understand what is being done and what still needs to be done. The types of new media and the ways that families and young children are using them are only going to continue to grow and evolve in the future. By stepping to the forefront of guiding families in using new media with their young children, libraries will meet a crucial need in today's society and continue to demonstrate the relevance and value they bring to their communities. \&

6. Zhen Chai, Cynthia O. Vail, and Kevin M. Ayres, "Using an iPad Application to Promote Early Literacy Development in Young Children with Disabilities," Journal of Special Education 48, no. 4 (2015): 268-78; Cori M. More and Jason C. Travers, "What's App with That? Selecting Educational Apps for Young Children with Disabilities," Young Exceptional Children 16, no. 2 (2013): 15-32; Christopher J. Rivera et al., "Using a Multicomponent Multimedia Shared Story Intervention with an iPad to Teach Content Picture Vocabulary to Students with Developmental Disabilities," Education and Treatment of Children 40, no. 3 (2017): 327-52; Angi Stone-MacDonald, "Using iPad Applications to Increase Literacy Skills for Children PreK to Grade 3 with Disabilities," Young Exceptional Children 18, no. 3 (2015): 3-18; Teresa Jane Prendergast, "Mapping the Early Literacy Ecology of Children with Disabilities in their Homes and Communities: Perspectives from Parents and Children's Librarians," (PhD thesis, University of British Columbia, Vancouver, 2018), https://bit.ly/2LjuNUB.

7. Jerome V. D’Agostino et al., "Introducing an iPad App into 
Literacy Instruction for Struggling Readers: Teacher Perceptions and Student Outcomes," Journal of Early Childhood Literacy 16, no. 4 (2016): 522-48.; Kathy Hirsh-Pasek et al., "Putting Education in 'Educational' Apps: Lessons from the Science of Learning," Psychological Science in the Public Interest 16, no. 1 (2015): 3-34.

8. Katie A. Paciga and Chip Donohue, Technology and Interactive Media for Young Children: A Whole Child Approach Connecting the Vision of Fred Rogers with Research and Practice (Latrobe, PA: Fred Rogers Center for Early Learning and Children's Media at Saint Vincent College, 2017), www.fredrogerscenter.org/wp-content/uploads/2017/07 /Technology-and-Interactive-Media-for-Young-Children .pdf.

9. See https://awelearning.com/early-literacy-station for more information.

10. Claudia Haines and Paula Langsam, "Thinking Sideways: Computational Thinking and Early Literacy," Public Library Association (PLA) webinar, December 13, 2018, www.ala.org/pla/education/onlinelearning/webinars /ondemand/sideways.

11. J. Elizabeth Mills et al., "Results from the Young Children,
New Media, and Libraries Survey: What Did we Learn?" Children \& Libraries 13, no. 2 (2015): 26-35.

12. We plan to publish the findings from the 2018 supplemental questions in future publications.

13. It is possible that the response rate is lower than the 2014 survey due to the expanded length of the 2018 survey.

14. Victoria Rideout, “The Common Sense Census: Media Use by Kids Age Zero to Eight” (San Francisco: Common Sense Media, 2017): 263-83.

15. Sonia Livingstone, Alicia Blum-Ross, and Jennifer Pavlick, "In the Digital Home, How Do Parents Support Their Children and Who Supports Them?," Parenting for a Digital Future, Aug. 1, 2018, https://blogs.lse.ac.uk/parenting4 digitalfuture/2018/02/06/in-the-digital-home/.

16. Rideout, The Common Sense Census: Media Use By Kids Age Zero to Eight.

17. Mills et al., "Results from the Young Children, New Media, and Libraries Survey."

18. Livingstone, Blum-Ross, and Pavlick, "In the Digital Home, How Do Parents Support Their Children and Who Supports Them?" 